\title{
A família como fator de risco e de proteção na gestação, parto e pós-parto
}

\section{The family as a risk factor and protection during pregnancy and postpartum}

\author{
Adriana Navarro Romagnolo ${ }^{1}$, Aline Oliveira da Costa $^{2}$, Neliane Lazarini de \\ Souza $^{3}$, Valéria de Carvalho Oliveira Somera ${ }^{4}$, Miria Benincasa ${ }^{5}$
}

\section{Resumo}

O objetivo da pesquisa se constituiu em analisar os fatores de risco e de proteção relacionados às questões familiares em dois casos de puérperas que viveram a experiência de um parto normal com assistência humanizada. Foi realizada uma entrevista semiestruturada para investigar a Gestação o Parto e PósParto e um questionário sócio demográfico. Para a análise dos dados, foi realizada análise qualitativa com análise de conteúdo. A participação ativa do cônjuge pôde ser entendida como fator principal de proteção. Observou-se que a forma como a relação familiar se constitui desde antes do momento da gestação pode influenciar diretamente no ciclo gravídico-puerperal. Considera-se que os fatores de risco e os fatores de proteção vivenciados durante a gestação se perpetuam durante o puerpério, acrescidos das demandas da maternidade. Sugere-se maior investimento de profissionais de saúde em intervenções para consolidação e estruturação da rede de apoio durante a gestação e no pós-parto.

Palavras-chave: Família. Fatores de risco e de proteção. Puerpério. Maternidade. Saúde da mulher.

\begin{abstract}
The aim of the research was to analyze the risk and protection factors related to family issues in two cases of puerperal women who experienced a normal childbirth with humanized assistance. A semi-structured interview was conducted to investigate the pregnancy, childbirth, postpartum and a socio-demographic questionnaire. For the analysis of the data, it was performed a qualitative analysis with content analysis. The active participation of the spouse could be understood as the main factor of protection. It was observed the constitution of the family relationship since before the moment of pregnancy can directly influence the pregnancy-puerperal cycle. It is considered that the risk and protection factors experienced during pregnancy perpetuate during the puerperium and increased by the demands of maternity. It is suggested a greater investment from health professionals in interventions for consolidation and structuring of the support network during pregnancy and postpartum.
\end{abstract}

Keywords: Family. Risk and protection factors. Puerperium. Maternity. Woman health.

\footnotetext{
1 Mestranda em andamento em Psicologia da Saúde pela Universidade Metodista de São Paulo. E-mail: adriananavarro. psicologia@gmail.com

2 Mestranda em Psicologia da Saúde pela Universidade Metodista de São Paulo.

3 Graduação em Psicologia pela Universidade Metodista de São Paulo.

${ }^{4}$ Graduação em Psicologia pela Universidade Metodista de São Paulo. Especialista em Psicanálise pelo Centro de Estudos Psicanalíticos.

5 Doutora em Psicologia do Desenvolvimento Humano pela USP. Pesquisadora e orientadora do Programa de Pós-Graduação em Psicologia da Saúde da Universidade Metodista de São Paulo e professora do curso de Psicologia da Universidade de Taubaté.
} 


\section{Introdução}

A família representa o agente socializador primário do indivíduo. Além de oferecer suporte, apoio e orientações, fornece exemplo de como viver, amar, sentir, cuidar de si e cuidar do outro. Dentro do sistema familiar o sujeito é ligado a crenças, valores e tradições que estão diretamente relacionados com os cuidados com a saúde. As ligações familiares possuem a capacidade de influenciar a forma com a qual os indivíduos percebem e vivenciam o processo saúde-doença, bem como nas necessidades de cuidado com seus membros. Este padrão se repete no período de gestação, parto e pós-parto (PRATES; SCHMALFUSS; LIPINSKI, 2015).

No que diz respeito ao ciclo gravídicopuerperal, entende-se que o apoio familiar é de extrema importância, pois pode ser fundamental no manejo de uma série de demandas especificas do pós-parto. Tornar-se mãe é uma das transições importantes e difíceis da vida adulta. A gravidez e o puerpério são períodos cruciais, tanto biológicos, quanto psicológicos, devido às alterações fisiológicas que preparam a gestante para o parto, nascimento e cuidados posteriores. Nesta fase torna-se imprescindível a revisão dos papéis sociais e familiares (DELLE FAVE et al., 2013).

Diante de todas essas transformações biológicas, psicológicas e sociais é comum que o casal assuma a gravidez conscientes das alterações biológicas, contudo, desconsiderem e desconheçam as transformações psíquicas oriundas da gestação, sobretudo nas relações sociais. A família tende a tornar-se a principal rede de apoio e suporte durante esse período, podendo ser considerada como um fator de risco, ou um fator de proteção no puerpério (MELO et al., 2015).

Alguns autores apontam sobre a importância da família no que diz respeito ao desenvolvimento. Para Shaffer (2005), o papel familiar se dá como fonte de segurança, afeto, proteção e bem-estar. Outros autores apontam que a família pode ser considerada o sistema mais importante na vida dos indivíduos, tendo em vista que, quando não cumpre o seu papel de proteção, pode servir como um fator de risco para o desenvolvimento de seus membros (PATIAS; GABRIEL; DIAS, 2012). Parte-se das concepções que tanto a gestação e maternidade como as relações familiares são fenômenos complexos e multifatoriais. A literatura indica que, quando apresentada como um fator de risco, a dinâmica familiar pode contribuir para a ocorrência de depressão pós-parto, dificuldades no aleitamento materno, dificuldades no vínculo mãe-bebê, dentre outros aspectos (LEVANDOWSKI; PICCININI; LOPES, 2008; PATIAS; GABRIEL; DIAS, 2012).

Fatores de risco podem estar presentes em características individuais (sexo, genética, características psicológicas, entre outros); como também em fatores ambientais (nível socioeconômico, estresse, características familiares, falta de apoio social, entre outros). Desta forma, considera-se que fatores de risco são as condições e/ou variáveis que se associam a uma probabilidade alta de resultados negativos e/ou indesejáveis que podem comprometer a saúde, bem-estar ou desempenho social do indivíduo (MORAIS, 2009; PATIAS; GABRIEL; DIAS, 2012).

Os fatores de proteção modificam, melhoram ou alteram a resposta do indivíduo a ambientes hostis, sendo assim, podem ser entendidos como condições ou variáveis que diminuem os fatores de risco. $\mathrm{O}$ mesmo autor ressalta que fatores protetivos podem ser características individuais, como exemplo, autoestima e autonomia; ou características familiares, como exemplo, afetividade, ausência de negligência, entre outros (HUTZ, 2002).

Será compreendido como família neste estudo, tanto a estrutura nuclear original quanto a recémorganizada. Embora a rede de apoio familiar envolva outras pessoas, além do companheiro, o que se espera, em especial dos pais, é que participem ativamente da criação dos filhos, pois possuem uma 
forte contribuição para o desenvolvimento mental e físico dos mesmos. É de suma importância, contudo, que eles possam reduzir a ansiedade, angustia e depressão durante o pré-natal, pois os níveis de ansiedade paterno e materno podem influenciar no desenvolvimento do bebê e da criança (TOHOTOA et. al., 2012).

As características de um pai que demostra um envolvimento ideal durante o período gravídico, seria: um pai presente, disponível, sendo um participante ativo da gravidez, estando presente nas consultas do pré-natal; nos cursos destinados as gestantes; na sala de parto disposto a cortar o cordão umbilical, dando todo suporte e apoio emocional a parturiente, e ajudando-a em todas as questões burocráticas que envolvem o nascimento (ALIO et al., 2013).

O envolvimento paterno é de suma importância durante o período gravídico, tendo grande impacto sobre o mesmo, indicando considerável redução de riscos. Um exemplo disso, é a menor incidência de bebês com baixo peso quando a participação paterna é ativa da gestação ao parto. Além de diminuir os riscos, o envolvimento paterno pode melhorar o resultado do parto, pois os pais podem influenciar os comportamentos maternos, podem diminuir comportamentos negativos durante a gravidez, reduzir o estresse materno ao cuidar das questões logísticas e financeiras. Esta postura tende a aumentar materno durante a gestação e parto (ALIO et. al. 2013).

O envolvimento paterno efetivo possibilita, além dos benefícios apontados anteriormente, uma série de resultados positivos para o bebê, sendo eles: o incentivo ao aleitamento materno, o fortalecimento ao desenvolvimento do bebê e do vínculo pai-filho $\mathrm{e}$, consequentemente, maior capacidade social e regulação emocional. Esses resultados fazem com que a presença do pai seja fundamental para o desenvolvimento familiar saudável (SILVA et al., 2016).
$\mathrm{O}$ apoio paterno durante o período gravídico vai além da provisão material, podendo ser compreendido pela sua participação em atividades direcionadas às gestantes, auxiliando-a em todas as questões que estejam relacionadas à chegada do bebê, oferecendo apoio emocional, auxiliando com o planejamento do parto ou a escolha do nome do filho, pois, um pai realmente envolvido com a gravidez está preocupado com a mãe e com o bebê, e se mantém informado sobre os detalhes, para que a gestante tenha uma gravidez saudável. O pai envolvido na gestação encoraja a gestante e a tranquiliza a respeito das transformações do seu corpo, e de que ela conseguirá ser uma boa mãe. Embora gestar e parir sejam atividades exclusivas da mulher, o homem, ocupando sua posição enquanto companheiro e pai, também é receptor das alterações gravídicas vivenciadas pela mãe de seu filho (ALIO et al., 2013; MELO et al., 2015).

O objetivo da presente pesquisa foi analisar os fatores de risco e de proteção relacionados às questões familiares em dois casos de puérperas que passaram pelo processo de parto com assistência humanizada conforme preconizado pelo HumanizaSUS4 (ANDRADE; LIMA, 2014).

Essa pesquisa se justifica por estudos anteriores que indicam a importância da intervenção psicológica durante o ciclo gravídico-puerperal, mais especificamente durante o pré-natal com o intuito de proporcionar um puerpério mais leve para a mulher e sua rede de apoio (ARRAIS; ARAÚJO, 2016; ARRAIS; MOURÃO; FRAGALLE, 2014; CIRIK et al., 2016; CUNHA et al., 2012), e também por estudos que apontam a pouca quantidade de artigos publicados sobre intervenção psicológica durante a gravidez como fator preventivo de conflitos puerperais (ROMAGNOLO et al., 2017). 


\section{Método}

Esse artigo é um recorte de um projeto financiado pela agencia de fomento FAPESP em Políticas Públicas. Trata-se de uma pesquisa exploratória com análise qualitativa e descritiva com duas participantes que viveram a experiência de um parto normal com assistência humanizada. No estudo original contou-se com a coleta de dados de 140 participantes em situação de pós-parto. Apesar da amostra geral ter sido aleatória, por conveniência, a escolha destes dois casos fundamentou-se em características comuns entre eles (Tabela - 1), mas com desfechos diferentes. Ambas têm a mesma faixa etária, com relacionamentos estáveis, mesmo nível sociocultural e econômico, mesma profissão e moram na mesma cidade. Além destas semelhanças, escolheram a mesma equipe para assistir ao parto, que ocorreu com aproximadamente dois meses de diferença. Estas participantes foram selecionadas, inclusive, porque observou-se que, dentro da amostra de 60 participantes, seus relatos mostraramse emblemáticos quanto ao tema família como fator de proteção e de risco. Este estudo cumpriu os procedimentos éticos definidos pela lei 466/12, com aprovação pelo Comitê de Ética tendo o número do parecer 896.875, emitido em 26/11/2014.

\begin{abstract}
Amostra
A amostra por conveniência foi composta de 2 mulheres que vivenciaram a experiência de um parto normal com assistência humanizada, segundo o que é preconizado pelo humanizaSUS4 (ANDRADE; LIMA, 2014). Os critérios para a inclusão na amostra além dos determinados acima são: a) ter passado pelo processo de parto há, pelo menos, 2 meses e, no máximo, 36 meses; b) ser o único filho(a), mesmo que tenha tido gestações anteriores c) estar em um relacionamento conjugal estável durante o parto.
\end{abstract}

Tabela 1 - Caracterização das Participantes

\begin{tabular}{lll}
\hline & & Participantes \\
\hline Dados & A. & B \\
\hline Idade & 30 & 31 \\
Estado Civil & Casada (Mora Junto) & Casada (Civil e Religioso) \\
Tipo de parto & Vaginal sem epidural, sem & Vaginal sem epidural, sem \\
Acompanhante no parto & ocitocina e sem episiotomia & ocitocina e sem episiotomia \\
Sexo do bebê & Marido & Marido \\
Idade do bebê & Masculino & Feminino \\
Semana gestacional da data do parto & 3 meses & 5 meses \\
\hline
\end{tabular}

Fonte: Os Autores.

\section{Instrumentos}

\section{Entrevista Aberta}

Segundo Bleger (1998), além de um recurso da clínica, a entrevista é uma técnica bastante útil para a pesquisa científica em Psicologia. O que diferencia a entrevista Psicológica de outros tipos de entrevistas é o objetivo, que neste modelo, pretende investigar aspectos psicológicos. $\mathrm{Na}$ entrevista aberta há maior liberdade para que o entrevistador altere a ordem das perguntas, insira novas questões elucidativas e levante hipóteses sobre o tema. Sua 
característica principal, e que depende da habilidade do entrevistador, é inserir estímulos para que a entrevistada, à sua maneira, traga as informações que se pretende encontrar através dos objetivos da pesquisa. Nesta entrevista foram investigados três grandes temas: Gestação, Parto e Pós-Parto. Embora o objetivo da pesquisa envolva analisar o pós-parto, foi necessário investigar a participação da família e do cônjuge também no período da gravidez e do parto, no sentido de compreender a continuidade desta participação. Para conhecer a gestação, foi solicitado que a participante fizesse um relato criterioso deste período, do pré-natal, da preparação para o parto, do planejamento para a recepção deste bebê, do envolvimento familiar nesta gestação, da relação com o obstetra, etc. Foi incluída uma investigação minuciosa sobre a gestação e parto a fim de colher informações sobre os fatores de risco e proteção presentes durante este período. $\mathrm{Na}$ investigação do parto foi solicitado um relato detalhado deste, abordando desde o início do trabalho de parto, ainda em casa até a saída da maternidade. Quanto ao pós-parto, buscamos conhecer como foi a chegada em casa, a rede de apoio, sentimentos e angústias vividos, cuidados do bebê, cuidados pessoais, rotina, etc.

\section{Questionário Sociodemográfico}

Este questionário é composto de 25 questões, sendo a maior parte objetiva. $\mathrm{O}$ instrumento foi desenvolvido pelas próprias pesquisadoras para o presente estudo. Nele constam questões sobre dados pessoais, financeiros, ocupacionais, questões relacionadas ao período gestacional, ao parto, ao pós-parto e à saúde do bebê.

\section{Procedimentos}

Após a aprovação do Comitê de Ética em Pesquisa da Universidade Metodista de São Paulo, foi feito um convite virtual para possíveis interessadas através de redes sociais. Foram selecionadas páginas do facebook e blogs que tinham como objetivo principal a discussão de temas relacionados à gestação, parto e pós-parto. Entrou-se em contato com os administradores das redes e apresentou-se a pesquisa. Alguns responsáveis faziam o convite para seus seguidores e outros autorizavam que a equipe de pesquisa realizasse o convite através de um texto em cada página escolhida. As mulheres que se interessavam entravam em contato com as pesquisadoras por um aplicativo de troca de mensagens próprio do facebook ou por e-mail quando eram oriundas de blogs. Foram avaliadas 140 mulheres de São Paulo (capital e interior) e Minas Gerais (interior). Assim que as participantes foram contatadas e cumpriram os critérios estabelecidos para compor a amostra, foram informadas de forma mais detalhada sobre os objetivos da pesquisa. Após concordarem em participar, assinaram o Termo de Consentimento Livre e Esclarecido e foi agendado data e local para a entrevista. Foram necessários dois encontros com cada participante.

Durante os encontros foi realizada uma entrevista semiestruturada para investigar três grandes temas: Gestação, Parto e Pós-Parto. Embora a proposta fosse discutir o impacto da família e do companheiro no puerpério, investigouse sua participação durante a gestação e parto para compreender o processo destas relações de cuidado. Buscando conhecer a gestação, foi solicitado que as participantes fizessem um relato criterioso de sua gestação, do pré-natal, da preparação para o parto, do planejamento para a recepção deste bebê, do envolvimento familiar nesta gestação, da relação com o obstetra, etc. Na investigação do parto foi solicitado um relato detalhado deste, abordando, desde o início do trabalho de parto, ainda em casa até a saída da maternidade. Quanto ao pós-parto, buscou-se conhecer como foi a chegada em casa, a rede de apoio, sentimentos e angústias vividos, cuidados do bebê, cuidados pessoais, rotina, etc. Nesta mesma data foi aplicado o questionário sociodemográfico. 
Para a análise dos dados, foi realizada análise qualitativa. As entrevistas foram transcritas e foi realizada a análise de conteúdo (BARDIN, 1977), seguindo seu modelo baseado em três fases: préanálise, exploração do material e tratamento dos resultados (inferência e interpretação). Inicialmente foi realizada uma pré-análise buscando as primeiras hipóteses ou questões norteadoras relacionadas aos objetivos do trabalho. Estas foram organizadas em indicadores, ou seja, unidades de categorização, buscando semelhanças e contrastes ao tema investigado. Tanto indicadores quanto unidades de categorização foram divididas pelos períodos de Gestação (notícia da gravidez, ida às consultas de pré-natal, participação em cursos preparatórios para a maternidade, etc.), Parto (envolvimento na escolha do parto, presença no momento do nascimento, interesse pelos primeiros cuidados, etc.) e pós-parto (cuidados com a mãe, cuidados com o bebê, presença, etc.). Posteriormente foram identificadas unidades de registro, explorando e descrevendo todo seu conteúdo. As unidades de registro que se relacionavam foram agrupadas em uma categoria. As categorias estabelecidas para este estudo - família como fator de risco e de proteção - estão apresentadas neste estudo a partir de falas emblemáticas das participantes.

\section{Resultados e Discussão}

Os resultados e a discussão serão apresentados a partir das categorias encontradas na Análise de Conteúdo, ou seja, Família como fator de risco e Família como fator de proteção, que resultaram em: Categoria 1: Fatores de Risco e Proteção na Gestação e Parto; Categoria 2: Família como fator de risco no puerpério; Categoria 3: Família como fator de proteção no puerpério.

\section{Categoria 1: Fatores de Risco e Proteção na Gestação e Parto}

Conforme Delle Fave et al. (2013), tornar-se mãe é uma das transições importantes e difíceis da vida adulta. A gravidez e o puerpério são períodos cruciais tanto biológicos quanto psicológicos, devido às alterações fisiológicas que preparam a gestante para o parto, nascimento e cuidados posteriores; além de propiciarem a necessidade de rever seus papéis sociais e familiares. $\mathrm{Na}$ fala das duas participantes podemos observar o quanto a gestação é um momento relevante na vida da mulher, e como pode provocar sentimentos ambivalentes, na descoberta da gravidez:

\section{Participante B.:}

"Nossa, nem sei. Eufiqueifeliz. Eufiqueiassustada porque meu marido ficou muito assustado."

"Então, foi assim, mudança, muita mudança de uma vez. Foi uma mudança completa, de uma vez...".

\section{Participante A.:}

"Difícil acreditar, a gente demora... eu não acredito até agora que já tive bebe, foi tudo muito rápido".

"Às vezes eu nem acredito... é bem diferente de tudo".

Muitos autores ressaltam que os fatores de risco e de proteção não são estáticos, mas fazem parte de um processo e dependem de outros aspectos, como por exemplo, as características individuais, o momento do desenvolvimento o qual o indivíduo se encontra, a situação a qual está vivenciando, dentre outros fatores. No que se refere às situações de pós-parto e maternidade, sabe-se que a família é apenas um dos aspectos, desta forma, há a necessidade de considerar outros fatores que podem aumentar as situações de risco ou de proteção. A análise mais focada em um único fator pode proporcionar uma compreensão mais ampla sobre o tema. Ainda assim, vale ressaltar que os fenômenos analisados são complexos e multifatoriais (PATIAS; GABRIEL; DIAS, 2012; TEIXEIRA; DIAS, 2010). 
Nas falas das participantes, podemos observar alguns fatores de risco e proteção durante a gestação, a começar pelos fatores de risco:

\section{Participante B:}

"Nãofoi planejada, mas assim, você vai perceber pela história que foi um ano bem conturbado [...] Assim, a gravidez era planejada porque estávamos tentando, mas a gente não imaginava de jeito nenhum que ia vir na mudança".

"Ele tinha tido... Ele estava com um pouco de síndrome do pânico [...] estava bem pesado [...] Pra mim, principalmente, porque ele não estava muito bem e eu tinha que sustentar os dois [...] Ele disse "eu não dou conta nem de cuidar de mim como é que eu vou tomar conta de um nenê".

"E eu estava com a mesma doença da menina [...] Cai o mundo [...]"

Em seu relato, não identificamos fatores de proteção durante a gestação. $\mathrm{Na}$ análise dos dois casos, podemos observar uma dicotomia entre as participantes, pois no relato da participante $A$, não identificamos fatores de risco, exceto, a gravidez não planejada, que no entanto, foi muito bem recebida:

Não foi planejado. Eu tive dengue e eu tomava anticoncepcional normal a anos. E quando eu tive dengue eu não consegui me alimentar nem tomar o anticoncepcional [...] Era dificil acreditar. Eu não acredito até agora que eu tive bebê! [...] Ahh ele ficou besta! Porque foi de madrugada. Aí ele me abraçou, a gente ficou na cama ainda. Ele chorou ainda. Foi uma coisa assim... De emoção. Chorou de emoção. Deixa que a gente se conhece a gente sempre falou de ter filho.

Podemos identificar ainda, como fator de proteção, um cônjuge muito envolvido durante a gestação, principalmente no que tange as questões relacionadas a via de parto, além de uma família, muito interessada e participativa. Prates, Schmalfuss e Lipinski (2015) sugerem que o apoio oferecido pela familia é capaz influenciar no bemestar do indiviuo, positiva ou negativamente. Sua participação ativa tona-se exemplo de cuidado e atenção, que pode ser replicado, neste caso, da mãe para o bebê.

Ele [Cônjuge] ficou muito impressionado com aquilo e falou: nossa, de jeito nenhum eu quero que meu filho nasça de cesária. A não ser que precise. Então não foi difícil de convencê-lo não. Com dois vídeos... foi bem fácil. E a gente assistiu $o$ Renascimento do parto e ele adorou.

Então eles [Família] estavam ansiosos para saber se era um menino uma menina.

Aí eu falei para eles: então, eu queria agradecer a presença de vocês, que a nossa familia é muito importante e ela vai aumentar. Aí, ficou um silêncio assim, ninguém estava entendendo. Daqui a pouco começou uma gritaria. Todo mundo começou a gritar, foi muito passado. Meu pai já saiu da sala, assim, foi pra cozinha. Começou a chorar. Que ele é todo forte, assim [...] Foi bem divertido.

Mais uma vez, observa-se o apoio da familia a todo o processo gravídico-puerperal. Para Melo et al. (2015), durante este período a familia, tanto pregressa quanto atual tendem a ser o principal suporte e com mais impácto na presença de afetos positivos relacionados as incertezas dessa nova etapa.

A literatura indica que, quando apresentada como um fator de risco, a dinâmica familiar pode contribuir para a ocorrência de depressão pós-parto, dificuldades no aleitamento materno, dificuldades no vínculo mãe-bebê, dentre outros aspectos (LEVANDOWSKI; PICCININI; LOPES, 2008; PATIAS; GABRIEL; DIAS, 2012). 
Categoria 2: Família como Fator de Risco no Puerpério

Delle Fave et al. (2013), colocam que as relações são fontes importantes de experiências positivas e negativas entre os seres humanos. A relação conjugal disfuncional e a falta de apoio e envolvimento do parceiro no pós-parto e puerpério são consideradas como fatores de risco para o desenvolvimento da depressão pós-parto, que pode ser caracterizada por perda do interesse, prazer, humor, fadiga, alterações do sono e apetite, perda de concentração, sentimentos de culpa e pensamentos suicidas. No relato da participante B. podemos notar a dificuldade que o marido teve em desenvolver sua função paterna:

"Quando acabou, eu passei muito mal. Eu tive um choque hipovolemico depois do parto [...] Ai ela olhou e disse «vou ter que te mandar pra UTI, porque o que você tem é o maior incidente de morte materna [...] Estava comigo [Cônjuge] ele chorou muito. Eu lembro de ver ele virado de costa. Ele virou de costa, pegou a nenê e chorou".

"Ele disse: - Eu não dou conta nem de cuidar de mim como é que eu vou tomar conta de um nenê?".

"Na verdade ele morria de medo de pegar ela e quando ela nasceu ela foi pro colo dele e ficou quase três horas no colo dele... ele chorou muito".

Neste discurso observa-se que o companheiro não consegue atender as expectativas relacionadas à função paterna em que deveria concentrar-se em ser um pai presente, disponível, participativo na gravidez, e também, não conseguiu apoiar a gestante em suas dificuldades durante e gestação e parto. Os autores apontam que faz parte da paternidade estar presente nas consultas do pré-natal; nos cursos destinados as gestantes; na sala de parto, disponibilizar-se para cortar o cordão umbilical, oferecer suporte e apoio emocional a parturiente e ajudá-la em todas as questões burocráticas que envolvem o nascimento (ALIO et. al., 2013).

Melo et al. (2015) acrescentam que o envolvimento paterno durante o período gravídico deveria ir além da provisão material, podendo ser compreendido pela sua participação em atividades direcionadas às gestantes, auxiliando em todas as questões que estejam relacionadas a chegada do bebê. Para os autores, além de todo o apoio emocional a mulher, o homem, ao ocupar sua posição enquanto companheiro e pai, também será receptor das alterações gravídicas vivenciadas pela mãe de seu filho.

Os sentimentos que aparecem nos cuidados de um recém-nascido podem envolver dificuldades e inseguranças envoltas pelo temor do casal e podem estar relacionados à falta de experiência e à ideia de que o bebê é um ser frágil, que necessita de cuidados mais delicados. Essas dificuldades e inseguranças podem estar associadas às novidades que a maternidade propõe, que exige da mulher e do companheiro um processo lento e gradual de incorporar a nova condição de serem pais. Este período do ciclo vital exige que os pais se tornem cada vez mais seguros e capacitados para realizarem os cuidados e que, os sentimentos de insegurança e ansiedade, frequentemente experienciados durante o pós-parto imediato, sejam menos constantes no decorrer do tempo (LEVANDOWSKI; PICCININI; LOPES, 2008; SILVA et al., 2016).

No caso da participante B, por exemplo, segundo as percepções da participante, o marido demonstrou dificuldade em perceber as transformações psíquicas, pois, de acordo com Melo et al. (2015), é normal que o casal assuma a gravidez, conscientes das alterações biológicas, contudo, desconsiderem e desconheçam as transformações psíquicas oriundas da gestação, sobretudo nas relações sociais.

Por outro lado, quando as puérperas não acreditam nas habilidades do companheiro, é comum que elas possam inibir a participação ou até mesmo excluí-los dos cuidados com o bebê, o que pode ser prejudicial para o desenvolvimento da criança, pois ela necessita, impreterivelmente que ambos os pais assumam papéis complementares para compor um desenvolvimento saudável (ALIO et al., 2013). 
Alguns estudos apontam que há uma tendência de que as puérperas procurem primeiramente seus familiares para que possam obter auxílio diante dos problemas enfrentados na maternidade, pois são eles que representam sua rede social de apoio. Desta forma, é importante considerar os contextos os quais estas mulheres estão inseridas, pois são esses sujeitos que terão influência durante as resoluções dos problemas apresentados nos cuidados com o recém-nascido (PRATES; SCHMALFUSS; LIPINSKI, 2015).

Embora o papel do cônjuge esteja ressaltado em nossa análise, devido à importância que este papel assume no puerpério, a seguir, observamos nas falas das participantes, a busca de auxílio e ajuda neste período, nos outros membros da família.

\section{Participante B.:}

"O mais dificil pra mim foi a minha mãe não me ajudar."

"Se ela [mãe] vier pra me ajudar, ela vai ajudar no que ela quiser e não no que eu preciso. De qualquer forma me ajuda. Se ela vier e eu estiver precisando dormir e eu falar: - Toma, fica um pouquinho com ela que eu vou dormir. - ela fala: Não. Vou lavar roupa”.

"Minha mãe não consegue me ajudar muito... Minha mãe faz umas comprar no supermercado, uma coisa ou outra assim só."

A dicotomia entre as participantes permanece, pois, não identificamos fatores de risco durante $o$ puerpério da participante $\mathrm{A}$. Observamos que a mesma, opta por dispensar o auxílio dos familiares, pois, o côjuge se mostra suficiente para auxiliá-la em tudo que precisa:

"Mas o A. ficou comigo os 30 dias. Ele tinha cinco dias de direito e ele pegou férias. Então ele ficou os 30 dias aqui comigo. Foi a melhor coisa que aconteceu".
Categoria 3: Familia como Fator de Proteção no Puerpério

Diante da demanda imposta pelo puerpério, as mães parecem dizer que estão aptas para cuidarem dos seus filhos, desde que exista alguém que possa cuidar dela (DELLE FAVE et al., 2013). Pode-se verificar que essa demanda de apoio e envolvimento por parte da mãe, no que se refere ao envolvimento dos familiares no puerpério, na fala das duas participantes:

\section{Participante B:}

"Meu marido tirou quinze dias de férias, ele ficou quinze dias comigo e aí eu entrei meio em pânico de pensar que ele ia voltar a trabalhar e eu ia ficar sozinha."

"Meu marido me ajudou muito. Muito, muito, muito. Mas...”.

"Ele fazia comida, levava lá pra cima, porque eu não aguentava subir e descer escada. Não aguentava nada. Eu estava muito fraca."

\section{Participante A:}

Os 30 primeiros dias são os mais difíceis... mas o A. ficou comigo, ele tinha cinco dias de direito e pegou férias e foi a melhor coisa que aconteceu, porque ter alguém de fora pra te ajudar tipo mãe e sogra ia ser muito ruim, porque elas não conhecem minha casa, meu jeito de cozinhar... ai o A. ficou comigo e foi ótimo, ele acordava de madrugada pra me ajudar.

"É bem dificil depender das outras pessoas sendo que você está apta pra fazer tudo... às vezes minha mãe vem aqui dai eu falo: eu dirijo e você fica com ele, e ai eu já passo em uns 5 ou 6 lugares diferentes".

"Minha mãe teve filho há 30 anos, meu marido não entende nada de criança, ele entende do nosso filho só”. 
"Eu não preciso de alguém que venha aqui cuidar do meu filho, do meu filho eu sei cuidar. Eu preciso de alguém que venha aqui pra cuidar de mim”.

De acordo com Delle Fave et al. (2013), o efeito protetor advindo das relações positivas, satisfatórias e confiantes com o parceiro, pais, e familiares em geral, nos meses seguintes após o parto, são fatores protetivos para os estados de mal-estar, depressão, ansiedade, sentimentos de vazio e fracasso. Sentimentos esses, que geralmente acometem as mães no pós-parto devido à relação simbiótica com a criança. Podemos observar no discurso da participante A. o estabelecimento de uma relação positiva com o parceiro e com a família durante todo o ciclo gravídico puerperal.

Silva et al. (2016) consideram que, muitas vezes, o companheiro é a única ou a principal referência da puérpera em seu convívio domiciliar, desta forma, é ele que se configura como aquele o qual ela mais poderá contar para realizar os cuidados com ela e com o bebê. Desta forma, acredita-se que quando bem informado e preparado, este ator pode promover a segurança e consolidar a estrutura familiar. O envolvimento paterno ideal trata-se de um pai que consola e protege a gestante, ouvindo-a, e se certificando de que ela esteja tão confortável quanto for possível, garantindo o bem-estar dela e do bebê (ALIO et al., 2013).

\section{Análise das Categorias}

Ao analisarmos as categorias, conforme foi colocado anteriormente observamos uma dicotomia entre as participantes, de forma que a participante A. apresenta-se com muitos fatores de proteção, durante a gestação, parto e puerpério, enquanto a participante B. apresenta-se com muitos fatores de risco durante a gestação e parto, apresentando fatores de proteção apenas no puerpério, quando seu cônjuge consegue se mostrar presente.
Nos discursos trazidos pelas participantes, observou-se que a A. traz uma vivência familiar mais protetiva desde antes da gestação. $\mathrm{O}$ afeto familiar apareceu nos relatos sobre a descoberta da gestação por ela e pelo cônjuge, ao contarem sobre a gravidez para a família; na escolha da equipe de parto, na confiança com a equipe ainda que tivesse um parto pélvico; no sucesso com a amamentação e nos cuidados com o filho, bem como a participação familiar nesses cuidados. Desta forma, foi possível perceber que as relações familiares se mantiveram durante a gravidez e proporcionarem um puerpério mais sadio, fazendo com que a família fosse um fator de proteção durante todo o processo. Esta proximidade e apoio estão associadas, segundo a literatura, a uma maior probabilidade de resultados positivos e melhoram a resposta da mãe às demandas provocadas pela maternidade (HUTZ, 2002; MORAIS, 2009; PATIAS; GABRIEL; DIAS, 2012).

"Eu estava tranquila. Eu estava bem. Eu não sei como eu sabia isso, mas eu estava muito calma. Eu era mais calma de todos, não sei porque".

\section{[Parto] "Eu me senti tranquila o tempo todo".}

"Então eu estava me sentindo bem, eu sabia que tudo ia dar certo, não sei porque. Mesmo tendo um parto com um pouco mais de risco, eu estava tão convicta que aquilo ia dar certo. Foi rápido e deu tudo certo. Então, eu me sentia tranquila. Todas as pessoas que eu queria estavam ali".

A participante $B$, entretanto, relatou uma convivência familiar com complicações, também anteriores a gestação, não podendo contar com a família de origem para lidar com as adversidades deste novo momento do ciclo vital e, consequentemente, como fator de proteção. Em seu discurso a participante trouxe uma relação conturbada com a mãe, síndrome do pânico do cônjuge, bem como ausência de relações sexuais no casamento, fazendo com que a notícia da gestação fosse inesperada. 
"O mais dificil pra mim foi a minha mãe não me ajudar."

"Ele tinha tido... Ele estava com um pouco de sindrome do pânico [...]".

[Quanto á vida sexual] "Na verdade não, porque já estava muito ruim antes de engravidar".

Estas condições podem ser entendidas, como indesejáveis, ou seja, comprometem o bem-estar da gestante, tornando-se fatores de risco, segundo o conceito de Morais (2009) e Patias, Gabriel e Dias (2012). Desta forma, foi possível perceber que os fatores familiares contribuíram para que ela tivesse complicações durante a gestação. Além disso, teve complicações durante o parto, dentre elas um choque hipovolêmico com necessidade de ficar internada dois dias na UTI; bem como dificuldades no puerpério, como por exemplo: anemia, sentimentos de solidão, dificuldades na amamentação, bem como apresentou sinais de depressão pós-parto. Assim, foi possível perceber que as relações familiares podem ter contribuído para as complicações, fazendo com que a família seja um fator de risco no que diz respeito ao ciclo gravídico-puerperal.

Não foi nosso objetivo investigar a participação ou a intervenção profissional, contudo, os fatores de risco que ser apresentam no pós-parto podem ser observados, mesmo que de forma embrionária, no período gestacional. Logo, sugerese maior investimento de profissionais de saúde em intervenções para consolidação e estruturação da rede de apoio durante a gestação, um prénatal que atenda as demandas de atenção integral a saúde da mulher, com profissionais sensíveis às manifestações psicológicas e sociais, que podem realizar intervenções que neutralizem os fatores de risco ou estimulem fatores de proteção. Uma modalidade para isso são os modelos de assistência em grupo, como o pré-natal psicológico, proposto por Araújo e Arrais (2016), onde há espaço para que as gestantes falem de incômodos que vão além do desconforto físico.

\section{Considerações Finais}

Foi possível compreender que a forma como a relação familiar se constitui desde antes do momento da gestação pode influenciar diretamente no ciclo gravídico-puerperal. Tais relações puderam ser percebidas desde o preparo para a chegada deste filho; na reação ao receberem a notícia da gestação; nas angústias e expectativas da gestação, nas vivências durante o trabalho de parto e nas diversas formas de lidar com as demandas do pós-parto. Considera-se que os fatores de risco e os fatores de proteção vivenciados durante a gestação se perpetuam durante o período do puerpério, porém acrescidos das demandas da maternidade.

Diante dos discursos apresentados, foi possível compreender a importância e a necessidade da participação do companheiro e da família nos cuidados com a puérpera e o recém-nascido tanto pelo cuidado em si, quanto pelo significado atribuído por elas, tendo em vista que relataram sentirem-se felizes, acolhidas, cuidadas, olhadas e apoiadas pelos companheiros quando os mesmos dedicavam momentos de cuidado e atenção a elas.

Tais manifestações foram compreendidas como formas de carinho e amor, o que puderam fortalecer o vínculo e a afetividade e promover uma aproximação do casal, bem como uma sintonia e cumplicidade nos cuidados em parceria com o novo membro da família.

Por outro lado, quando houve a ausência desse cuidado e atenção, foi possível observar que as inseguranças esperadas no puerpério possuíram outro direcionamento, sendo mais difíceis de serem superadas, podendo encontrar barreiras e dificuldades na amamentação, no vínculo do relacionamento conjugal, na criação de um novo papel familiar com a chegada desse bebê, bem como em outras demandas especificas desse período, fatores esses os quais podem contribuir para a manifestação de sintomas depressivos. 
Sendo assim, embora o ato de cuidar seja culturalmente considerado naturalmente como responsabilidade da mulher, há momentos os quais elas também necessitarão de cuidados, como por exemplo, o puerpério. Desta forma, poder contar com uma rede social de apoio, com destaque à participação especifica do companheiro, facilita para que a mulher possa vivenciar esse período de uma forma mais positiva, bem como contribui para o desenvolvimento do bebê dentro do contexto cultural familiar.

Os autores sugerem que, para minimizar os prejuízos identificados no pós-parto, profissionais de saúde podem se dedicar a desenvolver modelos de intervenção que tenham como objetivo estruturar a rede de apoio da gestante para o período do puerpério. Investimentos como este podem ser vistos como promoção de saúde materno-infantil que, além de gerar bem-estar para a mulher, podem favorecer a consolidação de um vínculo satisfatório para o bebê.

O que pudemos observar é que, no contexto científico, pouco se tem feito no sentido de intervenções positivas durante a gestação. Essas intervenções preventivas e ações com as gestantes e com a família podem favorecer um processo de parentalidade e conjugalidade mais satisfatório em todo o contexto, inclusive trabalhando com a rede de apoio familiar, minimizando fatores de riscos e de vulnerabilidade e fortalecendo os recursos de apoio para a administração de um puerpério mais saudável.

\section{Referências}

ALIO, A. P. et al. A community perspective on the role of fathers during pregnancy: a qualitative study. $B M C$ Pregnancy and Childbirth, London, 2013. Disponível em: <http://bmcpregnancychildbirth.biomedcentral.com/ articles/10.1186/1471-2393-13-60>. Acesso em: 27 dez. 2017.
ANDRADE, M. A. C.; LIMA, J. B. M. C. O modelo obstétrico e neonatal que defendemos e com qual trabalhamos. 2014. In: BRASIL. Ministério da Saúde. Humanização do parto e do nascimento. Brasília, 2014. (Cadernos HumanizaSUS, v. 4, p. 19-46). Disponível em: $\quad<$ http://www.redehumanizasus.net/sites/default/ files/caderno_humanizasus_v4_humanizacao_parto. pdf\&gt;016>. Acesso em: 27 dez. 2017.

ARRAIS, A. R.; ARAUJO, T. C. C. F. Pré-natal psicológico: perspectivas para atuação do psicólogo em saúde materna no Brasil. Revista da SBPH, Rio de Janeiro, v. 19, n. 1, p. 103-116, jun. 2016. Disponível em: $\quad<$ http://pepsic.bvsalud.org/scielo.php?script=sci_ arttext\&pid $=$ S1516-08582016000100007\&lng $=$ pt\&nrm =iso $>$. Acesso em: 25 out. 2017.

ARRAIS, A. R.; MOURAO, M. A.; FRAGALLE, B. O pré-natal psicológico como programa de prevenção à depressão pós-parto. Saúde e Sociedade, São Paulo, v. 23, n. 1, p. 251-264, mar. 2014. Disponível em: <http://www. scielo.br/scielo.php?script $=$ sci_arttext\&pid $=$ S0104$12902014000100251 \& \operatorname{lng}=$ en\&nrm=iso $>$. Acesso em: 25 out. 2017.

BARDIN, L. Análise de conteúdo. Lisboa: Ed. 70, 1977.

BLEGER, J. Temas em psicologia: entrevista e grupos. São Paulo: M. Fontes, 1998.

CIRIK, D. A. et al. The impact of prenatal psychologic and obstetric parameters on postpartum depression in late-term pregnancies: a preliminary study. Taiwanese Journal of Obstetrics \& Gynecology, Taipei, v. 55, p. 374378, 2016. Disponível em: <https://www.sciencedirect. com/science/article/pii/S102845591630002X>. Acesso em: 25 out. 2017.

CUNHA, A. B. et al. A importância do acompanhamento psicológico durante a gestação em relação aos aspectos que podem prevenir a depressão pós-parto. Saúde e Pesquisa, Maringá, v. 5, n. 3, p. 579-586, set./dez. 2012. Disponível em: <http://periodicos.unicesumar.edu.br/ index.php/saudpesq/article/view/2427/1812>. Acesso em: 27 dez. 2017.

DELLE FAVE, A. et al. A longitudinal study on motherhood and well-being: Developmental and clinical implications. Terapia Psicológica, Santiago, v. 31, n. 1, p. 21-33, 2013. Disponível em: <http://www. scielo.cl/scielo.php?script=sci_arttext\&pid $=$ S0718$48082013000100003 \& \operatorname{lng}=\mathrm{es} \& \mathrm{nrm}=\mathrm{iso}>$. Acesso em: 27 dez. 2017.

HUTZ, C. (Org.). Situações de risco e vulnerabilidade na infância e adolescência: aspectos teóricos e estratégias de intervenção. São Paulo: Casa do Psicólogo, 2002. 
LEVANDOWSKI, D.; PICCININI, C.; LOPES, R. Maternidade adolescente. Estudos de Psicologia, Campinas, v. 25, n. 2, p. 251-263, 2008. Disponível em: $\quad<$ http://www.scielo.br/scielo.php?script $=$ sci arttext\&pid=S0103-166X2008000200010\&lng=en\&nr $\mathrm{m}=\mathrm{iso}>$. Acesso em: $27 \mathrm{dez} .2017$.

MELO, M. R. et al. Conhecimento de homens sobre o trabalho de parto e nascimento. Escola Anna Nery Revista de Enfermagem, Recife, v. 19, n. 3, p. 454-459, jul./set. 2015. Disponível em: <http://www.scielo.br/pdf/ ean/v19n3/1414-8145-ean-19-03-0454.pdf $>$. Acesso em: 27 dez. 2017.

MORAIS, N. A. Trajetórias de vida de crianças e adolescentes em situação de vulnerabilidade social: entre o risco e a proteção. 2009. Tese (Doutorado em Psicologia) - Universidade Federal do Rio Grande do Sul, Porto Alegre.

PATIAS, N. D.; GABRIEL, M. R.; DIAS, A. C. G. A família como um dos fatores de risco e de proteção nas situações de gestação e maternidade na adolescência. Estudos e Pesquisas em Psicologia, Rio de Janeiro, v. 13, n. 2, p. 586-610, 2012. Disponível em: <http://www. revispsi.uerj.br/v13n2/artigos/html/v13n2a11.html $>$. Acesso em: 27 dez. 2017.

PRATES, L. A.; SCHMALFUSS, J. M.; LIPINSKI, J. M. Rede de apoio social de puérperas na prática da amamentação. Escola Anna Nery Revista de Enfermagem,
Recife, v. 19, n. 2, p. 310-315, 2015. Disponível em: $<$ https://dx.doi.org/10.5935/1414-8145.20150042>. Acesso em: 25 out. 2017.

ROMAGNOLO, A. N. et al. Pré-natal psicológico: uma revisão sistemática sobre os modelos de avaliação e intervenção psicológicas no mundo. In: MOSTRA DE PSICOLOGIA DA SAÚDE, 10., ENCONTRO NACIONAL EM PSICOLOGIA DA SAÚDE: TRANSDISCIPLINARIDADE EM PSICOLOGIA DA SAÚDE,1., 2017, São Bernardo do Campo. Anais... São Bernardo do Campo: Universidade Metodista, 2017. p. 30

SHAFFER, D. R. Psicologia do desenvolvimento: infância e adolescência. Tradução de Cíntia Regina Pemberton Cancissu. São Paulo: Pioneira, 2005.

SILVA, E. M. et al. Participação do companheiro nos cuidados do binômio mãe e filho: percepção de puérperas. Revista de Pesquisa: Cuidado é Fundamental, Rio de Janeiro, v. 8, n. 1, p. 1-13, 2016. Disponível em: <http:// www.seer.unirio.br/index.php/cuidadofundamental/ article/view/5015/pdf_1824>. Acesso em: 25 out. 2017.

TOHOTOA, J. et al. Can father inclusive practice reduce paternal postnatal anxiety? A repeated measures cohort study using the hospital anxiety and depression scale. BMC Pregnancy and Childbirth, London, 2012. Disponível em: <http://www.biomedcentral.com/14712393/12/75>. Acesso em: 25 out. 2017. 
